\title{
ASSESSMENT OF CENTRALITY PROPERTIES OF AKURE ROAD NETWORK
}

\author{
Seun Daniel Oluwajana ${ }^{1}$, Olufikayo Oluwaseun Aderinlewo ${ }^{2}$, Adebayo Oladipo \\ Owolabi $^{3}$, Silvana Vivian Croope ${ }^{4}$ \\ ${ }^{1,2,3}$ Federal University of Technology, Department of Civil Engineering, Akure, Nigeria \\ ${ }^{4}$ Delaware Department of Transportation, Delaware, USA
}

Received 31 July 2012; accepted 15 November 2012

\begin{abstract}
Three 1-square mile of different urban street networks were extracted from Akure road network and developed into primal graphs. The resulting edges and nodes in the network were described by their distance matrix. Shortest paths across the nodes were calculated as well as the centrality measures. The edge length distribution analysis of the network studied showed a single peak distribution found in cities with a pattern realized over a historical process, which was out of the control of any central planning agency. Further investigation into the correlation between centrality measures showed that they captured different properties with correspondingly low values. Degree centrality was found to be correlated over the network. This was linked to the spatial restraint imposed on the network by land use. Information centrality values revealed that not all nodes in a network perform the same function since the network was found to perform better when some nodes were deactivated. However, analysis carried out revealed that the betweeness centrality and information centrality values, which capture the load and the ability of a network to respond to deactivation of a network, were of utmost importance in assessing the network.
\end{abstract}

Keywords: graph theory, road network, primal graph, centrality measures, self-organized cities.

\section{Introduction}

Transportation systems of regional and national extent are composed of networks of interconnected facilities, services and elements that function together as a whole. Therefore, a road network can be viewed as an assemblage of components and subsystems that work together to perform the same function. Hence, all transportation projects must be analyzed with due consideration for their position within a modal or intermodal network and their impacts on network performance (Bronzini, 2004). Transportation networks inherently have a node and link structure where the links represent linear features providing for movement such as highways and rail lines, and the nodes represent intersections. Thus, the principal data content of a node is its name or number and location. Links usually have characteristics such as length, directionality, number of travel lanes and functional class.

Roads are essential elements in topological maps, navigational maps and other types of maps. A road network consists of a lot of roads that are interwoven together (Zhang, 2004). The road network is a topological graph for expressing road information and is composed of nodes and edges: nodes indicate characteristic points such

${ }^{2}$ Corresponding author: faderin2010@yahoo.com 
as intersections, terminal points and so on and edges point out the connectivity among nodes. A network consists of access nodes and links connecting these nodes. In the case of transit networks, lines are included as well.

The network design problem in its simplest form is to find a set of links that has an optimal performance given a specific objective (Immers et al., 2004). The road network, which represents road information with nodes and edges, is generated through the connection procedure of different pairs of parallel line segments sequentially since a continuous road is looked upon as a sequence of pairs of parallel line segments (Nishijima and Watanabe, 1996).

Much research has been done to analyze the vulnerability of road networks and most of the methods were based on analyzing the topological structure of the network using graph theory (Zhang and Virrantaus, 2010). Graph theory deals with problems that have a graph (or network) structure and is therefore considered as a field of mathematical ideas about graphs. A graph is an abstract representation consisting of a number of points connected by lines. The points are called vertices and the lines are called edges. Graphs can be considered as a tool for modelling.

Urban development as well as the construction of transportation routes follows usually structural conditions. Economical rules, security issues or the best possible utilization of terrain are some basic principles for the emergence of typical structures in road networks. The knowledge of such patterns provides information about the design, history and development of an urban area as well as the functional organization of a town (Heinzle et al., 2007). Network analysis can be used to define or identify route corridors and determine travel paths, travel distances and response times. Network analysis may be used to assess the traffic volume impact of a road closure on adjacent roadways (Spring, 2004)

The network approach has been widely used in urban studies. Since the early sixties, extensive research has been carried out trying to link the allocation of land uses to population growth through lines of transportation. Such research has also sought to predict traffic flows given several topological and geometric characteristics of traffic channels or investigate the exchanges of goods and habits between settlements in the geographic space even in historical eras. Most if not all these approaches have been based on a quite simple, intuitive representation of networks which turns intersections into nodes and roads into edges (Porta et al., 2006). In this research work, the aim was to analyse Akure road network for its centrality properties.

\section{Methodology}

The method used for network analysis in this study was based on the primal approach where a spatial graph in which zero dimensional geographic entities (intersections) are turned into zero dimensional graph entities (nodes) placed in two dimensional Euclidean space and one dimensional graph entities such as street turned into one dimensional graph entities. Primal graphs are constructed by following a road-centreline-between-nodes rule, which ensures that real intersections are turned into graph nodes and real streets are turned into graph edges. All graph edges are defined by two nodes (the endpoints of the arc) and possibly several vertices (intermediate points of linear discontinuity). Intersections among edges were always located at nodes, edges followed the footprint of real streets as they appeared on the source map and all distances were calculated metrically. 
Three representative sections were sampled from Akure road network map (Fig. 1) obtained from the Ondo state Ministry of work and developed into graphs using the primal approach. All information was obtained from the map. Edges were assigned with weights, which represent the distance values of the roads between intersections. A graph $G$ was described by $L$, an $\mathrm{Nx}$ matrix whose entry $l_{i j}$ is the distance value or metric length associated with the street connecting $i$ and $j$.

Five indices of centrality were investigated over four cases of urban street networks spatially through the presentation of thematic maps and statistically by plotting their cumulative distributions. Centrality scores were calculated on nodes over the primal graphs. Thereafter, analogous primal layouts were produced with reference either to node or edge centrality.

In primal graphs, one edge is defined by just one pair of ending nodes by which the edge participates in the topology of the network as a whole. Consequently, centrality on one edge is simply equated to the average of the centralities of its defining pair of nodes. The following centrality properties were evaluated:

\subsection{Degree Centrality}

Degree centrality $C_{d}$ is the simplest definition of node centrality. It is based on the idea that

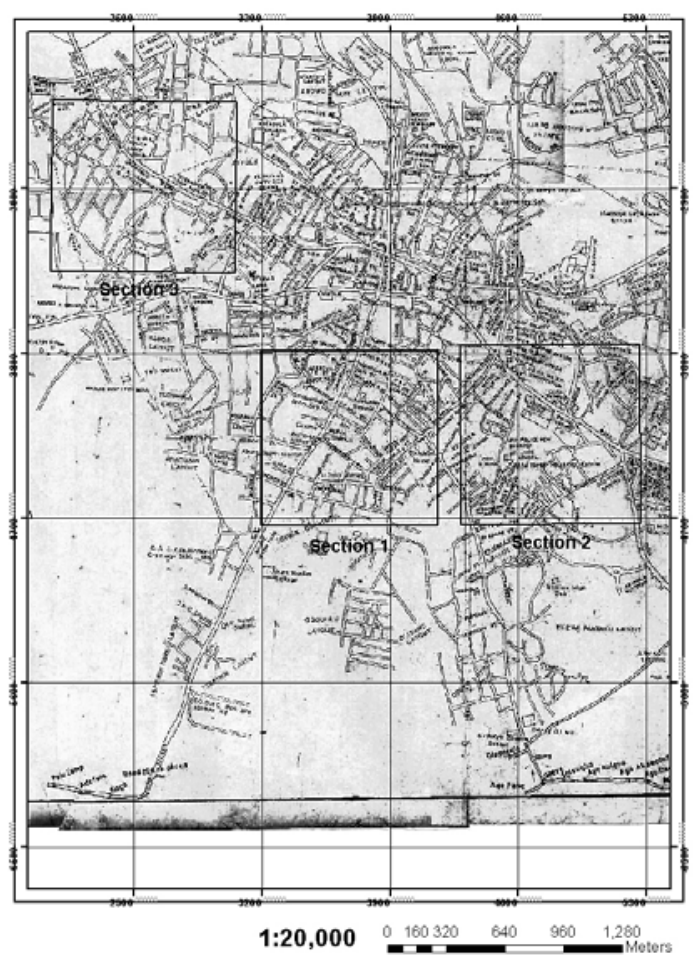

Fig. 1.

Map of Akure Showing the Sections Considered 
important nodes have the largest number of ties to other nodes in the graph (Porta et al., 2006). Degree centrality of node $i$ is defined as Eq. (1):

$C_{i}^{d}=\frac{\sum_{j=1, N} a_{i j}}{N-1}=\frac{k_{i}}{N}$

where $k_{i}$ is the degree of node $i$.

\subsection{Closeness Centrality}

Closeness centrality $C_{c}$ measures (metrically) to what extent a node $i$ is close to all the other nodes along the shortest path (Porta et al., 2006), and it is defined as Eq. (2):

$C_{i}^{c}=\frac{N-1}{\sum_{j \in g, j \neq i} d_{i j}}$

where $d_{i j}$ is the shortest path between nodes $i$ and $j$ defined in a valued graph as the smallest sum of edge lengths throughout all the possible paths in the graph between $i$ and $j$.

\subsection{Betweeness Centrality}

This is defined as the total number of shortest paths that pass through a node when the shortest paths are calculated between every pair of nodes (Porta et al., 2006). The betweeness centrality of node $i$ is defined as Eq. (3):

$C_{i}^{B}=\frac{1}{(\mathrm{~N}-1)(\mathrm{N}-2)} \sum_{j, k \in G, j \neq k \neq i} n_{j k}(i) / n_{j k}$

where $n_{j k}$ is the number of shortest path between nodes $j$ and $k$ and $n_{j k}(i)$ is the number of shortest path between $j$ and $k$ that contains node $i$.

\subsection{Straightness Centrality}

Straightness centrality $C^{s}$, originates from the idea that the efficiency of communication between two nodes $i$ and $j$ is equal to the shortest path length $d_{i j}$ (Porta et al., 2006). The straigthness centrality of node $i$ is defined as Eq. (4):
$C_{i}^{S}=\frac{1}{N-1} \sum_{j \in G, j \neq i} d_{i j}^{E u c l} / d_{i j}$

where $d_{i j}^{E u c l}$ is the Euclidean distance between nodes $i$ and $j$ along a straigth line. A normalization which captures to which extent the connecting route between nodes $i$ and $j$ deviates from the virtual straigth route.

\subsection{Information Centrality}

Information centrality, $C^{I}$ is a measure introduced so as to relate a node's importance to the ability of the network to respond to deactivation of that node (Porta et al., 2006). The network performance before and after a certain node is deactivated is measured by the efficiency, $E$ of the graph, $G$. The information centrality of node $i$ is defined as the drop in the network efficiency caused by the removal from $G$ of edges incident in $i$ (Eq. (5)):

$C_{i}^{l}=\frac{\Delta E}{E}=\frac{E[G]-E\left[G^{i}\right]}{E[G]}$

Now, the efficiency of the graph $G$ is defined as Eq. (6):

$$
E[G]=\frac{1}{N(N-1)} \sum_{i, j \in, i \neq j} d_{i j}^{\text {Eucl }} / d_{i j}
$$

where $G_{i}$ is the graph with $N$ nodes and $K-k_{i}$ edges obtained by removing from the original graph $G$ the edge incident in nodes $i$.

\section{Analysis and Interpretation of Results}

Three 1-square mile samples of different urban street-intersection network (Fig. 2) were obtained from a map of Akure street guide with scale $1: 20,000$. These were imported into GIS (Geographic Information System) environment and the primal graphs were 
constructed using node-centreline-approachbetween-node formats.

The three areas studied within Akure showed striking difference in the level of land development as well as the activities that take place within them. The basic structure observed over the planar road network embedded in real space is branching network (with no form of circuit network) which was distinguished by the presence of tree-like structure consisting of connected lines.

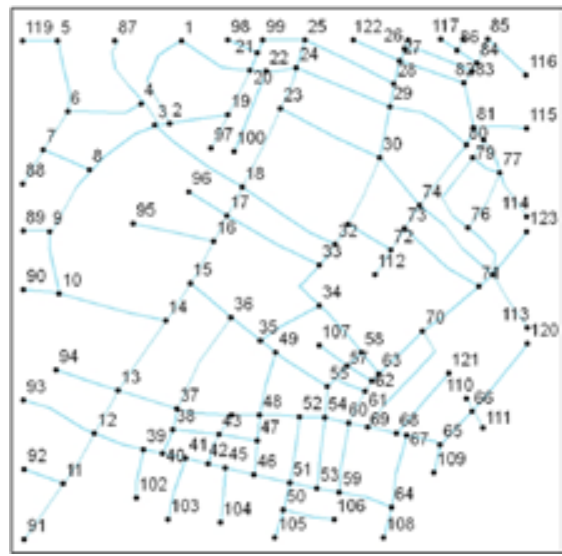

Network 1
Consequently, the following attributes were characteristic of the graphs:

- Weights: the weights corresponded to the distances between geodesic nodes;

- Sparseness: this property means that

$$
K \leq \frac{N(N-1)}{2} \text {; }
$$

- Connectedness: there exists at least one path connecting any couple of nodes.

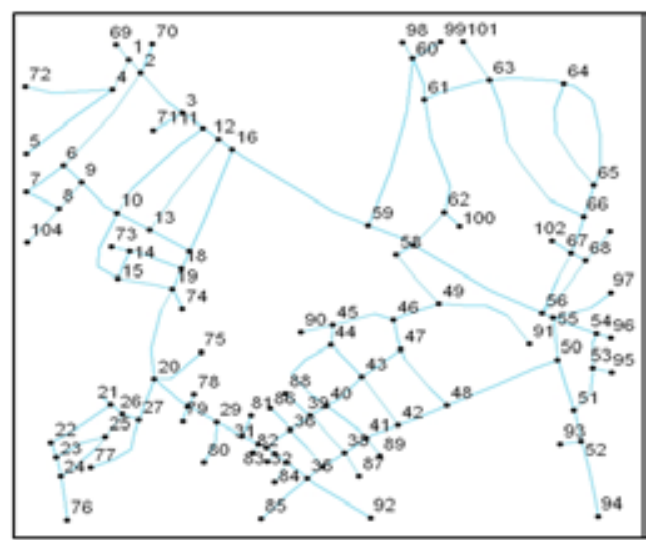

Network 2

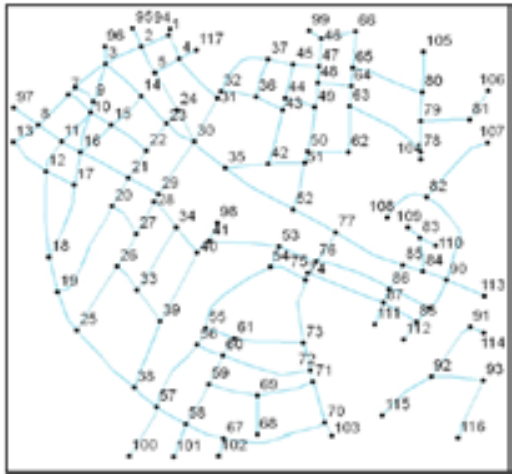

Network 3

Fig. 2.

Primal Graphs of the Networks 
In this analysis dead ends were considered as nodes since travel path from such an area uses of the nearest / or neighbouring nodes.

\subsection{Length Distribution of the Graph/ Network under Study}

The basic properties of primal graphs obtained from the three 1-square mile samples of the different urban street namely $N$ (the numbers of nodes), $N(L)$ (the number of edges), $<l>$ (average edge length) and $\sigma$ (standard deviation) are as given in Table 1.

Table 1

Basic Properties of the Primal Networks

\begin{tabular}{ccccc}
\hline \multicolumn{2}{c}{$\begin{array}{c}\text { Numbers Number } \\
\text { of nodes } \\
(\boldsymbol{N})\end{array}$} & $\begin{array}{c}\text { Average } \\
\text { of edges } \\
\boldsymbol{N}(\boldsymbol{L})\end{array}$ & $\begin{array}{c}\text { stangth } \\
\text { length } \\
\text { deviation } \\
\sigma_{\boldsymbol{l}}\end{array}$ \\
\hline \hline 1 & 123 & 155 & 156.774 & 51.806 \\
2 & 104 & 126 & 144.603 & 77.309 \\
3 & 117 & 159 & 146.835 & 49.039 \\
\hline
\end{tabular}

However, the urban street network properties considered showed different patterns even though the same amount of land was considered. Also, the areas studied within Akure exhibit variations in the way the edge length is distributed as shown in Fig. 3.

$P\left(l_{1}\right), P\left(l_{2}\right)$, and $P\left(l_{3}\right)$ are the edge length distributions for networks 1,2 and 3 respectively. The edge length distribution $P(l)$ is defined by Eq (7):

$P(l)=\frac{N(l)}{L}$

where $N(l)$ is the number of edges/links with a particular length and $L$ is the number of links/edges in the network/graph under consideration.

Various kinds of cities can be divided into two broad classes namely:

a) Self-organized cities with pattern growing throughout its historical process, which is out of the control of any central planning agencies;

b) Planned cities with pattern realized over

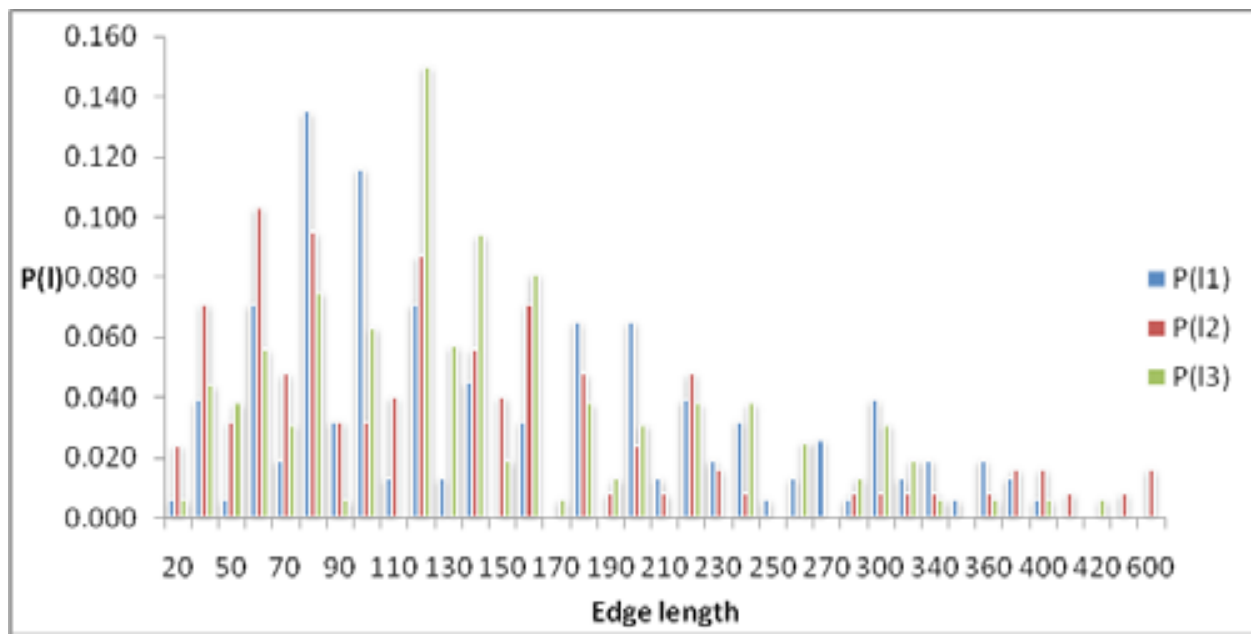

Fig. 3.

Probability Distribution $P(l)$ of Edge Lengths over the Networks 
a short period of time as a result of a single plan and usually exhibiting a grid like structure.

It was observed over the case of urban street networks considered that the length distribution $P(l)$ showed single peak distribution observed at $0.135,0.103$ and 0.150 respectively over network case studies 1,2 and 3 . This value corresponds to edge length of $80 \mathrm{~m}$ for network 1 , edge length $60 \mathrm{~m}$ for network 2 and $120 \mathrm{~m}$ for network 3 .

These single peak distribution exhibited is typical of cities/networks with growing pattern over a period of time out of the control of any central agency and multimodal distribution can only be observed over a city with pattern realized over short period of time (i.e. planned cities) due to the presence of a grid pattern. This suggests that Akure city is not planned as evidenced by the peak distribution observed from the three samples of urban street. These can be attributed to the presence of star like pattern characterized by hub like junctions with roughly parallel links with a set of links crossing the hub.

Akure network exhibits self-organized patterns because it spontaneously emerged from a historical process devoid of any central coordination. This can be linked to the scale free properties exhibited by the degree distribution.

\subsection{Analysis to Quantify the Importance of Nodes Considered in the Network}

Centrality properties were used to quantify the importance of the nodes in the network. These properties included the degree, betweeness, closeness and straightness centralities. The efficiency of the network was quantified by the information centrality of the networks. Also, some nodes in the networks were intentionally targeted to investigate the importance of certain nodes with degree 2, 3, 4 and 5 respectively. In order to quantify their importance, the distance matrix whose entry $l_{i j}$ corresponding to the edge length was used to evaluate the shortest path and various empirical formulas were applied thereafter.

\subsubsection{Degree Centrality}

In the analysis carried out, nodes with degree 1 stand for dead ends. Nodes with degrees 2, 3,4 , and 5 represent intersections. However, only a very limited numbers of nodes connect to 5 links and they lie mostly in urban areas. The degree centralities of graph 1 (network 1) range from 0.008 (for nodes with degree 1 ) to 0.041 (for nodes with degree 5). Also, degree centralities between 0.001 (for nodes with degree 1) to 0.039 (for nodes with degree 4) were obtained for Graph 2 (network 2). The values obtained for graph 3 (network 3 ) range between 0.009 (for degree 1) and 0.043 (for degree 5).

However, the degree centrality is local as it does not indicate how a node is positioned in an entire network but it does point to the importance of a node to the other nodes attached to it. The values obtained from the analysis were dependent on the number of nodes in the networks.

\subsubsection{Closeness Centrality}

The nodes in a network with high closeness centralities are those, which can be reached over short distances. The nodes in spatial networks near to the geometrical centroid of a network are much more likely to have high closeness centralities. Analysis carried out in this study show that the centrality properties of the nodes close to the source nodes selected arbitrarily have higher closeness centrality 
properties. This confirms the fact that the smaller the shortest path distances from the source node the higher the closeness centrality values obtained. Closeness centrality values obtained in the analysis carried out range from 0.05 to 0.4 for graph $1,0.05$ to 2.58 for graph 2 and 0.05 to 1.16 for graph 3 . The basic observation from the analysis carried out is that nodes with small shortest path values often have closeness centralities that are higher than those with higher values of the shortest path.

For network 1 , nodes 2 to $30,87,88$ and 96 to 100 have high closeness centrality properties because of their shortest path length from the source nodes. Also, nodes 2 to 20, 69 to 73 and 104 in network 2 have high centrality properties. Furthermore, nodes 2 to 17,20 to 24,26 to 32,34 to 37,40 to 45,47 to 49 , 64,94 to 99 and 177 also have high closeness centralities. However, the analysis carried out showed that nodes 2 and 4 are the closest for networks 1 and 2. For network 3, nodes 1 and 94 were the closest. The higher the closeness centrality, the more accessible the node is from the source node.

\subsubsection{Betweeness Centrality}

The betweeness centrality of a node measures how often a given node sits 'between' other nodes. Nodes that occur on many shortest paths between other nodes have higher betweeness than those that do not. A node that is between many is assumed to have a higher likelihood of being able to control information flow in the network. The betweeness centrality also refers to the load on a particular node and the higher the value obtained for betweeness, the more the node plays an important role in the network. The betweeness centralities for network 1 range from 0 to 0.008 , for network 2 from 0.001 to 0.01 and for network 3 from
0.001 to 0.009 . However, in all cases, node 1 recorded the highest values of betweeness centrality ranging from 0.008 to 0.01 .

\subsubsection{Straightness Centrality}

Straightness centrality originated from the idea that the efficiency of spatial network in distributing information might be measured by comparing the length of shortest path between nodes of a network. Straightness centrality is variance of efficiency centrality of a network otherwise known as the information centrality. It measures how much a connecting route between two geodesic nodes deviates from virtual straight connecting line. Straightness centrality assesses a network on its ability to spread information globally.

The straightness centralities obtained for the networks showed that nodes having straight sections that are equal to the shortest path length often have high values regardless of their position and numbers in the network. Consequently, the higher the deviation of a node from straight connecting routes, the less the straightness centrality values and vice versa.

The higher the straightness centralities of the nodes in a network, the smaller the deviation and the greater the ability of such nodes to spread information globally. The values of straightness for these analysis range from 0.001 to 0.008 for network $1,0.001$ to 0.01 for network 2 , and 0.001 to 0.013 for network 3 .

\subsubsection{Information Centrality}

Information centrality can be defined as the change in the efficiency of a network after deactivation of a node. However, the efficiency of the whole network was calculated and some nodes with degree 2, 3, 4 and 5 were tested in the network to quantify the importance of the nodes. 
Information centrality takes values in the interval of 0 and 1 . Information centrality depends on the length of the alternative paths that are used once a node is deactivated. In order to simulate artificial disruption of the network, the critical nodes in the network were "attacked" by targeting them and systematically removing them one after the other. Four nodes each in the network were attacked based on the prior knowledge of their properties.

In the analysis carried out it was observed that the efficiency for the whole network reduces in some cases and increases in others. For a meaningful comparison, a constant number of nodes were used. In this case, an increase in the efficiency of the network when some nodes are deactivated could be attributed to the fact that some nodes closer to the nodes deactivated can serve as alternative access routes, in order to traverse to other nodes. However, it was observed that there wasn't a sharp drop in the efficiency of the network and the whole network still remained connected together in a giant component after an attack on some nodes. There was a drop in the efficiency of the network, in some cases where nodes serving as bridge to other nodes where deactivated.

In the first network case-study considered, nodes $2,18,67$ and 75 were deactivated. When node 2 was deactivated the efficiency of the network (i.e. 0.00309) was greater than that obtained when all the nodes in the network were participating (i.e. 0.00304). This can be attributed to the presence of a nearby node that can create another path in order to get to other nodes in the network. This suggested that in some networks the role of a node reduces when there is another node that can perform the function of a node deactivated. An increase in the efficiency of the network was observed when node
75 was deactivated. This can be linked to the fact that node 75 linked to a dead end imposed by artificial boundary. When node 67 and 18 were deactivated, it was observed that the efficiency of the network dropped. Values of 0.00303 and 0.00280 were obtained suggesting that nodes that serve as link to a node having a higher degree plays an important role in a network.

In the second network case-study considered, nodes $2,16,20$ and 58 were investigated for their information centrality. However, out of these nodes tested, an improved performance was observed when node 20 was deactivated. When deactivated the value obtained was greater than when all the nodes of the network were intact. This can be attributed to the fact node 20 serves as a bridge to some nodes in the network because they link nodes that lead to dead ends. For all other nodes in the network, there was a drop in the efficiency of the network. In the third network casestudy, deactivation of nodes 2, 10, 13 and 84 resulted generally in a drop in the efficiency of the network.

\subsection{Correlation between Centrality Measures Investigated over the Networks}

The Pearson correlation coefficients between the various centrality measures showed a small positive correlation for the first two cases of urban networks studied (i.e. networks 1 and 2) with values of 0.128 and 0.057 . This indicates that as the degree centralities increase, the closeness centralities also increase. However, the resulting trend observed in network 3 showed a negative correlation with a value of -0.068 which can be attributed to the geographic nature of the area studied as there were only few links with dead ends with a majority of the links present being connected to neighbouring nodes. 
In addition, the latter trend showed by the third network reflects the level of land development experienced in such an area. For correlation between the other centrality measures, i.e. degree centrality plotted against betweeness centrality and straightness centrality, small positive correlation of 0.305 , 0.333 , and 0.262 were observed for the first relationship (i.e. degree centrality and closeness centrality) and $0.118,0.125,0.033$ for the second relationship (i.e. for degree centrality and straightness centrality).

The negative correlation coefficient obtained between degree centrality and closeness centrality signifies that the two centrality measures vary in opposite direction, i.e. a large values of one of the centrality measures tends to associate with small values of the other. Relatively moderate relationships of 0.627 and 0.679 were observed between closeness centrality and betweeness centrality as well as straightness centrality for network 1. Also, a similar trend was observed between closeness centrality and straightness centrality for network 3. All other correlations coefficients obtained over the networks exhibited weak relationships.

\subsection{Spatial Distribution of Centralities}

The spatial distribution of node centralities was represented graphically by using GIS colour supported coded map in which one of eight different colour codes was plotted on each node in the graph. These colour code represents eight classes of nodes with different centrality indices. Various classes that were defined in terms of multiples of the standard deviation $\sigma$ from average value are $[-\infty, \sigma]$, $[-3 \sigma,-2 \sigma],[-2 \sigma,-\sigma],[-\sigma, 0],[0, \sigma],[\sigma$, $2 \sigma],[2 \sigma, 3 \sigma],[3 \sigma, \infty]$. Eight colour codes were assigned to the deviations as shown by the legend in Fig. 4.
For each centrality value obtained for each network, the average as well as the deviation of each of the values from the average was obtained. Thereafter, the deviations were then grouped for each centrality value obtained in each network. Various average values were obtained from each network. The spatial distribution of the betweeness centralities tends to capture the continuity of prominent urban routes across a number of intersections, change in directions and focal urban spots. The closeness centralities were observed to group to higher scores. This is due to the artificial boundaries imposed by the 1-square mile boundary.

The resulting colour coded maps for the distribution of closeness centralities over the networks are as shown in Fig. 5. In a similar manner, colour coded maps were obtained for the distribution of betweeness and straightness centralities over the networks.

\section{Conclusion}

Analysis carried out on the edge length distribution of the network studied showed a single peaked distribution usually observed in cities with a pattern that evolved from a historical process rather than from agency plans. Consequently, the analysis identifies Akure as a self-organized city.

Investigation into the centrality properties of the nodes in the networks showed that various centrality measures capture different properties. Based on the degree centralities obtained, the analysis results showed that the nodes with the highest number of ties to other nodes in the network case studies (i.e. nodes with degrees 4 and 5) also indicated the highest degree centralities ranging from 0.039 to 0.041 . The maximum value of 0.041 was however recorded in network case study 3 . 


\section{0 \\ $[-\infty, \sigma][-3 \sigma,-2 \sigma] \quad[-2 \sigma,-\sigma] \quad[-\sigma, 0] \quad[0, \sigma] \quad[\sigma, 2 \sigma] \quad[2 \sigma, 3 \sigma] \quad[3 \sigma, \infty]$}

Fig. 4.

Eight Colour Codes Used for Representing the Standard Deviation from Average
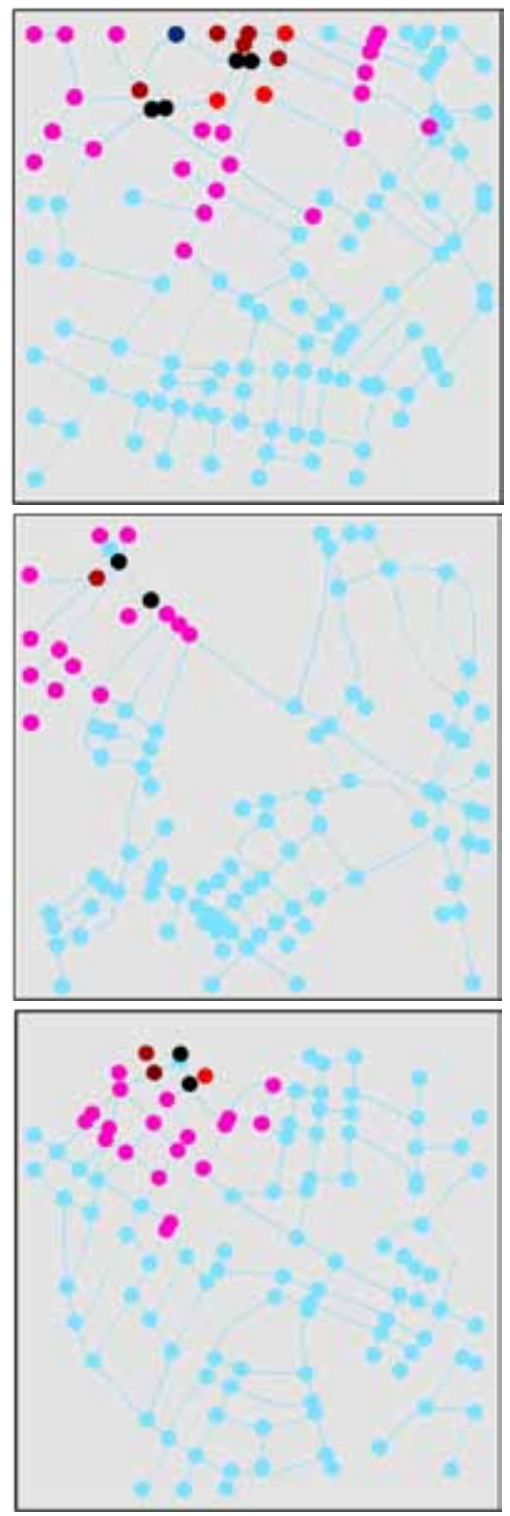

Fig. 5.

Spatial Distribution of Closeness Centralities over the Networks

jjtte 92 
In terms of the closeness centralities, nodes 2 and 4 were the closest in network case studies 1 and 2 with the highest centrality values ranging between 0.4 and 2.58 while nodes 1 and 94 were the closest in network case study 3 with the highest closeness centrality value of 1.16 . The maximum value was recorded in network case study 2 . In terms of the betweeness centralities, node 1 recorded the highest values of betweeness centrality in all the network case studies ranging from 0.008 to 0.01 with the maximum value (i.e. 0.01 ) being recorded in network case study 2 . In the case of the straightness centralities, the highest values ranged from 0.008 to 0.013 for the three network case studies, while the maximum value (i.e. 0.013 ) was obtained in network case study 3 for node 117. Lastly, in terms of the information centralities, nodes 2 and 20 gave the highest centrality values for network case studies 1 and 2 respectively, which was indicated by the increase in the network efficiency after their removal. Conversely, the removal of any node in network case study 3 resulted in loss of network efficiency indicating that its shortest paths deviate largely from straight lines.

The implication of these centrality values with respect to the nodes (especially those with high centrality values) is that it quantifies their level of accessibility from immediate surroundings and more distant places. A more central location tends to be visible, popular and more attractive to growth and development since it usually commands a more intensive land use and traffic flow. As the network becomes more complex, new central locations (intersections) emerge, which stimulate further growth in traffic activity.

Correlation analysis of the centrality values indicated small Pearson correlation coefficients over the three networks most of which were below 0.5 . Degree centrality values were found to be correlated over the network as a result of spatial constraints imposed on transportation by land use.

\subsection{Recommendations}

It is recommended that the intersections with the highest values of betweeness centralities (especially those represented as node 1) in each network case study should be given attention during further development of the city network since they can prove critical to ensuring free flow of traffic. Consequently, node 1 represents Odole street, Ajegunle street and Kola Adeyemi street junctions in network case studies 1, 2 and 3 respectively. In addition, analysis of Akure road network should be carried out on a larger scale by considering more sections or the entire network as a whole. Suitable software applications should also be considered for use in analysing the network and the results should be compared with those obtained in this study so as to verify their accuracy.

\section{References}

Bronzini, M.S. 2004. National transportation networks and intermodal systems. Handbook of Transportation Engineering. The McGraw-Hill Companies, Inc. USA. 11 p.

Heinzle, F.; Anders, K.H. 2007. Automatic detection of patterns in road networks: methods and evaluation. In Proceedings of the Joint Workshop Visualization and Exploration of Geospatial Data, XXXVI-4/W45, Stuttgart, Germany (CD-ROM).

Immers, B.; Egeter, B.; Nes, R.V. 2004. Transport network planning: theoretical notions. Handbook of Transportation Engineering. The McGraw-Hill Companies, Inc. USA. 33 p.

Nishijima, M.; Watanabe, T. 1996. An automatic extraction of road information on the basis of cooperative hypotheses interpretation mechanism. 
IAPR Workshop on Machine Vision Applications, Tokyo, Japan. 147-150.

Porta, S.; Crucitti, P.; Latora. V. 2006. The network analysis of urban streets: a primal approach, Environment and Planning B: Planning and Design. DOI: http://dx.doi.org/10.1068/ b32045, 33(5): 705-725.

Spring, G.S. 2004. Applications of GIS in transportation. Handbook of Transportation Engineering. The McGraw-Hill Companies, Inc. USA. 25 p.

Zhang, Q. 2004. Modeling structure and patterns in road network generalization. In Workshop on Generalization and Multiple Representations, Leicester, U.K. 1-7.

Zhang, Z.; Virrantaus, K. 2010. Analysis of vulnerability of road networks on the basis of graph topology and related attribute information. In Proceedings of the 13th AGILE International Conference on Geographic Information Science, Guimarães, Portugal. 1-4.

\section{PROCENA KARAKTERISTIKA CENTRALNOSTI PUTNE MREŽE AKURE}

\section{Seun Daniel Oluwajana, Olufikayo \\ Oluwaseun Aderinlewo, Adebayo \\ Oladipo Owolabi, Silvana Vivian Croope}

Sažetak: Tri kvadratne milje različite ulične mreže su izdvojene iz putne mreže Akure i razvijene u proste grafove. Dobijene grane i čvorovi mreže opisani su pomoću matrice rastojanja. Izračunati su najkraći putevi preko čvorova, kao i mere centralnosti. Analiza raspodele dužine grana ispitavane mreže pokazala je raspodelu sa jednim pikom u gradovima sa uzorkom ostvarenim preko istorijskog toka koji je izvan nadzora bilo koje agencije za centralno planiranje. Dalja ispitivanja korelacije između mera centralnosti pokazala su da postoje različite karakteristike uz odgovarajuće niske vrednosti. Ispostavilo se da stepen centralnosti korelira duž cele mreže. Ovo se dovodi u vezu sa prostornim ograničenjem mreže usled korišćenja zemljišta. Podaci o meri centralnosti pokazuju da svi čvorovi u mreži ne obavljaju istu funkciju jer se ispostavilo da mreža bolje funkcioniše kada su neki čvorovi deaktivirani. Međutim, sprovedena analiza pokazala je da su vrednosti međupoložene centralnosti i informacione centralnosti, koje prikazuju opterećenje i mogućnost mreže da odgovori na deaktivaciju, bile od najvećeg značaja za procenu mreže.

Ključne reči: teorija grafova, putna mreža, prosti graf, mere centralnosti, samoorganizovani gradovi. 